\title{
A study on relationship between workforce agility and knowledge sharing
}

\author{
Hamed Suofi", Mohammad Reza Hosnavi and Naser Mirsepasi
}

Department of Management and Accounting, Science and Research Branch, Islamic Azad University, Tehran, Iran

\section{CHRON I C L E A B S T RACT}

Article history:

Received 5 January 2014

Received in revised format

8 March 2014

Accepted 12 March 2014

Available online

14 March 2014

Keywords:

Knowledge sharing

Workforce agility

Malek Ashtar University of

Technology

\begin{abstract}
This paper presents an empirical survey to study the relationship between knowledge sharing and workforce agility among regular employees of Malek Ashtar University of Technology located in city of Tehran, Iran. The study uses two questionnaires for measuring knowledge sharing and workforce agility in Likert scale. In our survey, knowledge sharing consists of three dimensions of cognitive, structural and relationship while workforce agility includes seven dimensions including intelligence, maturity, perseverance and hard-working, creativity and innovation, being responsive, flexibility and information and communication. Using Pearson correlation ratio, the study has detected positive and meaningful relationships between various components of knowledge sharing, structural, relational and cognitive, and workforce agility ( $\mathrm{r}$ $=0.708$, P-value $=0.001$ )
\end{abstract}

(C) 2014 Growing Science Ltd. All rights reserved.

\section{Introduction}

The term of the agile workforce has been investigated for creating the agile organization, which receives superior environmental responsiveness in contexts of change (Li, 2012; Muduli, 2013). Some agility studies concentrate overly on the organization, paying special attention to the workforce. Breu et al. (2002) discussed an existing gap in agility research by reporting on the first empirical investigation to study how the pressures of organizational agility influenced on the workforce. They reported suggest that agile workforces acquire the five abilities of intelligence, competencies, collaboration, culture and information systems (IS). In terms of information technology (IT) characteristics, the determinants of workforce agility were found to have flexible infrastructure platforms, which support the rapid introduction of new IS and the enhancement of IT competencies across the entire workforce. The study also disclosed that information and communications technology applications could increase workforce agility most when applied for collaborative working.

*Corresponding author. Tel:+989126446322

E-mail addresses: hamedsuofi@yahoo.com (H. Suofi) 
Iravani and Krishnamurthy (2007) considered workforce management in repair/maintenance environments in which repair people were cross-trained to attend more than one kind of machine. They provided some insights into the design and control issues of repair/maintenance systems with cross-trained repair people. Workforce agility is commonly explained as a strategy, which helps profitability in rapidly changing, and uncertain production environments. Agility needs to be distinguished from the shorter term concept of flexibility, which is associated with daily operational issues. When there is insufficient level of workforce agility, some enterprises may have difficulty keeping pace with markets and technological changes (Rodina et al., 2003). Qin and Nembhard (2010) demonstrated the advantages of the RO-based agility, such as the asymmetric attitudes towards risk exposure and profitability, and the robustness to high uncertainty.

Knowledge sharing plays essential role for the development of business organizations (Gruber, 1995). According to Neches et al. (2011), constructing new knowledge-based systems today normally entails constructing new knowledge bases from scratch accomplished by building reusable components. System developers could then only require to worry about generating the specialized knowledge to the special task of their system. The new system could interoperate with existing systems, using them to execute some of its reasoning. In this way, problem-solving techniques, and reasoning services could all be shared among systems, which facilitate building larger and better systems, cheaply.

Neches et al. (2011) presented a vision of the future in which knowledge-based system development and operation was facilitated by infrastructure and technology for knowledge sharing. They also described an initiative currently under way to develop these ideas and recommended essential steps, which must be taken to realize this vision.

Tsai (2002) studied the effectiveness of coordination mechanisms on knowledge sharing in intraorganizational networks, which consist of both collaborative and competitive ties among organizational units. Internal knowledge sharing within a multiunit organization needs formal hierarchical structure and informal lateral relations as coordination mechanisms.

Tsai (2002) analyzed how formal hierarchical structure and informal lateral relations impacted knowledge sharing and how inter-unit competition could moderate the association between such coordination mechanisms and knowledge sharing in a relatively large, multiunit firm. Tsai (2002) explained that formal hierarchical structure has a substantial negative impact on knowledge sharing, and informal lateral relations, in the form of social interaction. It also maintains a substantial positive impact on knowledge sharing among units, which compete with each other for market share, but not among units, which compete with each other for internal resources.

Sherehiy et al. (2007) identified the global characteristics of agility, which could be used to all characteristics of enterprise including flexibility, responsiveness, speed, culture of change, integration and low complexity, high quality and customized products, and mobilization of core competencies.

\section{The proposed study}

This paper presents an empirical survey to study the relationship between knowledge sharing and workforce agility among regular employees of Malek Ashtar University of Technology in city of Tehran, Iran. The study uses two questionnaires for measuring knowledge sharing and workforce agility in Likert scale. In our survey, knowledge sharing consists of three dimensions of cognitive, structural and relationship while workforce agility includes seven dimensions including intelligence, maturity, perseverance and hard work, creativity and innovation, being responsive, flexibility and information and communication. The sample size of the study is determined as follows,

$n=\frac{N \times z_{\alpha / 2}^{2} \times p \times q}{\varepsilon^{2} \times(N-1)+z_{\alpha / 2}^{2} \times p \times q}$, 
where $N$ is the population size, $p=1-q$ represents the yes/no categories, $z_{\alpha / 2}$ is CDF of normal distribution and finally $\varepsilon$ is the error term. Since we have $p=0.5, z_{\alpha / 2}=1.96$ and $N=750$, the number of sample size is calculated as $n=254$. We distribute 340 questionnaires and managed to collect 258 properly filled ones. There were 31 questions associated with workforce agility and 28 questions were related to knowledge sharing and all questions were designed in Likert 1-5 scale. Cronbach alphas were calculated in the range of 0.75-0.90 and they were well above the minimum acceptable limit. Fig. 1 shows details of participants' personal charactersitics.

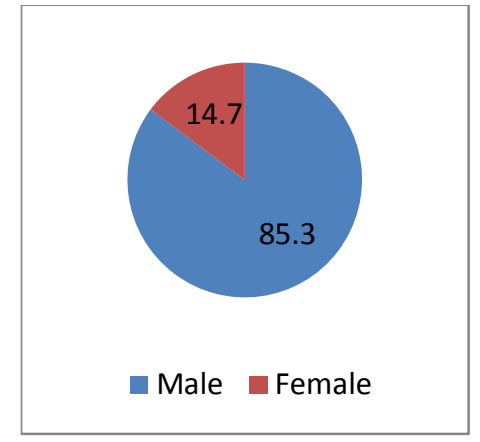

Gender

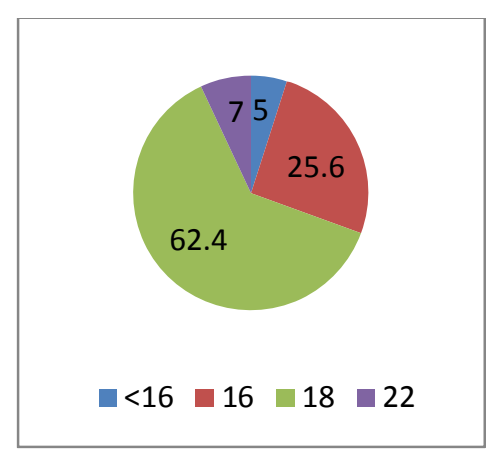

Years of education

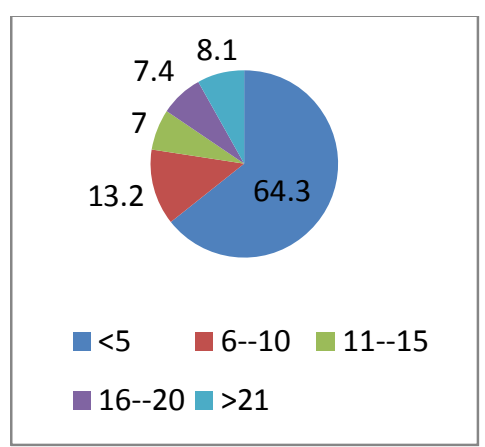

Years of job experience

Fig. 1. Personal characteristics of the participants

As we can observe from the results of Fig. 1, most people who participated in our survey were male with good educational background and relatively fair job experience. The mean scores given to workforce agility and knowledge sharing were calculated as 3.22 and 3.45, respectively. Kolmogorov-Smirnove test has also been applied to data and the results are Sig. $=0.051$ and Sig. $=0.090$ for workforce agility and knowledge sharing, respectively. Therefore, all data are normally distributed and we can use Pearson correlation test to verify the relationship between workforce agility components and knowledge sharing components. There are three main hypotheses associated with the proposed study of this paper as follows,

1. There is a positive and meaningful relationship between structural knowledge sharing and workforce agility.

2. There is a positive and meaningful relationship between relational knowledge sharing and workforce agility.

3. There is a positive and meaningful relationship between cognitive knowledge sharing and workforce agility.

\section{The results}

In this section, we present details of our findings on testing the relationship between knowledge sharing and workforce agility.

\subsection{The effect of structural knowledge}

Table 1 shows details of our Pearson correlation test between structural component of knowledge sharing and workforce agility. 
Table 1

The summary of Pearson correlation test for workforce agility and structural components of knowledge sharing

\begin{tabular}{|c|c|c|c|c|c|c|c|c|c|}
\hline & & Structural & Intelligence & Maturity & Hard working & Creativity & Responsiveness & Flexibility & Communication \\
\hline \multirow{2}{*}{ Structural } & $\mathrm{r}$ & 1 & - & - & - & - & - & - & - \\
\hline & $\mathrm{P}$-value & & - & - & - & - & - & - & - \\
\hline \multirow{2}{*}{ Intelligence } & $\mathrm{r}$ & 0.051 & 1 & - & - & - & - & - & - \\
\hline & $\mathrm{P}$-value & 0.412 & & - & - & - & - & - & - \\
\hline \multirow{2}{*}{ Maturity } & $\mathrm{r}$ & 0.055 & $0.672 * *$ & 1 & - & - & - & - & - \\
\hline & P-value & 0.376 & 0.000 & & - & - & - & - & - \\
\hline \multirow{2}{*}{ Hard working } & $\mathrm{r}$ & -0.008 & $0.700^{* *}$ & $0.743 * *$ & 1 & - & - & - & - \\
\hline & $\mathrm{P}$-value & 0.903 & 0.000 & 0.000 & & - & - & - & - \\
\hline \multirow{2}{*}{ Creativity } & $\mathrm{r}$ & $0.179 * *$ & $0.648^{* *}$ & $0.676^{* *}$ & $0.763 * *$ & 1 & - & - & - \\
\hline & P-value & 0.004 & 0.000 & 0.000 & 0.000 & & - & - & - \\
\hline \multirow{2}{*}{ Responsiveness } & $\mathrm{r}$ & $0.144^{* *}$ & $0.470^{* *}$ & $0.520 * *$ & $0.583 * *$ & $0.628^{* *}$ & 1 & - & - \\
\hline & $\mathrm{P}$-value & 0.021 & 0.000 & 0.000 & 0.000 & 0.000 & & - & - \\
\hline \multirow{2}{*}{ Flexibility } & $\mathrm{r}$ & $0.158^{* *}$ & $0.423 * *$ & $0.503 * *$ & $0.497 * *$ & $0.532 * *$ & $0.564 * *$ & 1 & - \\
\hline & P-value & 0.011 & 0.000 & 0.000 & 0.000 & 0.000 & 0.000 & & - \\
\hline \multirow{2}{*}{ Communication } & $\mathrm{r}$ & $0.138^{* *}$ & $0.557^{* *}$ & $0.578^{* *}$ & $0.611^{* *}$ & $0.563^{* *}$ & $0.498^{* *}$ & $0.558^{* *}$ & 1 \\
\hline & $\mathrm{P}$-value & 0.027 & 0.000 & 0.000 & 0.000 & 0.000 & 0.000 & 0.000 & \\
\hline
\end{tabular}

** Sig. $<0.5$

As we can observe from the results of Table 1, there is a positive and meaningful relationship between cognitive dimension and four workforce agility including creativity $(\mathrm{r}=0.179$, P-value $=$ $0.004)$, being responsiveness $(\mathrm{r}=0.144$, $\mathrm{P}$-value $=0.021)$, flexibility $(\mathrm{r}=0.158, \mathrm{P}$-value $=0.011)$ and communication $(\mathrm{r}=0.138$, P-value $=0.027)$.

\subsection{The effect of relational knowledge sharing}

Table 2 demonstrates details of our Pearson correlation test between relationship component of knowledge sharing and workforce agility.

Table 2

The summary of Pearson correlation test for workforce agility and relational components of knowledge sharing

\begin{tabular}{|c|c|c|c|c|c|c|c|c|c|}
\hline & & Relational & Intelligence & Maturity & $\begin{array}{l}\text { Hard } \\
\text { working }\end{array}$ & Creativity & Responsiveness & Flexibility & Communication \\
\hline \multirow{2}{*}{ Relational } & $\mathrm{r}$ & 1 & - & - & - & - & - & - & - \\
\hline & $\mathrm{P}$-value & & - & - & - & - & - & - & - \\
\hline \multirow{2}{*}{ Intelligence } & $\mathrm{r}$ & $0.629 * *$ & 1 & - & - & - & - & - & - \\
\hline & P-value & 0.000 & & - & - & - & - & - & - \\
\hline \multirow{2}{*}{ Maturity } & $\mathrm{r}$ & $0.621 * *$ & $0.672 * *$ & 1 & - & - & - & - & - \\
\hline & P-value & 0.000 & 0.000 & & - & - & - & - & - \\
\hline \multirow{2}{*}{ Hard working } & $\mathrm{r}$ & $0.675 * *$ & $0.700 * *$ & $0.743 * *$ & 1 & - & - & - & - \\
\hline & P-value & 0.000 & 0.000 & 0.000 & & - & - & - & - \\
\hline \multirow{2}{*}{ Creativity } & $\mathrm{r}$ & $0.609 * *$ & $0.648 * *$ & $0.676^{* *}$ & $0.763 * *$ & 1 & - & - & - \\
\hline & $\mathrm{P}$-value & 0.000 & 0.000 & 0.000 & 0.000 & & - & - & - \\
\hline \multirow{2}{*}{ Responsiveness } & $\mathrm{r}$ & $0.511 * *$ & $0.470 * *$ & $0.520 * *$ & $0.583 * *$ & $0.628 * *$ & 1 & - & - \\
\hline & $\mathrm{P}$-value & 0.000 & 0.000 & 0.000 & 0.000 & 0.000 & & - & - \\
\hline \multirow{2}{*}{ Flexibility } & $\mathrm{r}$ & $0.462 * *$ & $0.423 * *$ & $0.503^{* *}$ & $0.497 * *$ & $0.532 * *$ & $0.564 * *$ & 1 & - \\
\hline & $\mathrm{P}$-value & 0.000 & 0.000 & 0.000 & 0.000 & 0.000 & 0.000 & & - \\
\hline \multirow{2}{*}{ Communication } & $\mathrm{r}$ & $0.569 * *$ & $0.557 * *$ & $0.578^{* *}$ & $0.611^{* *}$ & $0.563 * *$ & $0.498 * *$ & $0.558 * *$ & 1 \\
\hline & $\mathrm{P}$-value & 0.000 & 0.000 & 0.000 & 0.000 & 0.000 & 0.000 & 0.000 & \\
\hline
\end{tabular}

\footnotetext{
** Sig. $<0.5$
} 
The results of Table 2 indicate that there were positive and meaningful relationship between relational dimension and all seven components of workforce agility including intelligence $(\mathrm{r}=0.629$, $\mathrm{P}$-value $=0.000)$, maturity $(\mathrm{r}=0.621, \mathrm{P}$-value $=0.000)$, hard-working $(\mathrm{r}=0.675, \mathrm{P}$-value $=0.000)$, creativity $(\mathrm{r}=0.609, \mathrm{P}$-value $=0.000)$ and being responsiveness $(\mathrm{r}=0.511$, $\mathrm{P}$-value $=0.000)$, flexibility $(\mathrm{r}=0.462, \mathrm{P}$-value $=0.000)$ and communication $(\mathrm{r}=0.569, \mathrm{P}$-value $=0.000)$.

\subsection{The effect of relational knowledge sharing}

Table 3 presents details of the Pearson correlation test between cognitive component of knowledge sharing and workforce agility.

Table 3

The summary of Pearson correlation test for workforce agility and cognitive components of knowledge sharing

\begin{tabular}{|c|c|c|c|c|c|c|c|c|c|}
\hline & & Cognitive & Intelligence & Maturity & $\begin{array}{l}\text { Hard } \\
\text { working }\end{array}$ & Creativity & Responsiveness & Flexibility & Communication \\
\hline \multirow{2}{*}{ Cognitive } & $\mathrm{r}$ & 1 & - & - & - & - & - & - & - \\
\hline & $\mathrm{P}$-value & & - & - & - & - & - & - & - \\
\hline \multirow{2}{*}{ Intelligence } & $\mathrm{r}$ & $0.492 * *$ & 1 & - & - & - & - & - & - \\
\hline & $\mathrm{P}$-value & 0.000 & & - & - & - & - & - & - \\
\hline \multirow{2}{*}{ Maturity } & $\mathrm{r}$ & $0.546^{* *}$ & $0.672 * *$ & 1 & - & - & - & - & - \\
\hline & $\mathrm{P}$-value & 0.000 & 0.000 & & - & - & - & - & - \\
\hline \multirow{2}{*}{ Hard working } & $\mathrm{r}$ & $0.491 * *$ & $0.700 * *$ & $0.743 * *$ & 1 & - & - & - & - \\
\hline & P-value & 0.000 & 0.000 & 0.000 & & - & - & - & - \\
\hline \multirow{2}{*}{ Creativity } & $\mathrm{r}$ & $0.507 * *$ & $0.648^{* *}$ & $0.676^{* *}$ & $0.763 * *$ & 1 & - & - & - \\
\hline & P-value & 0.000 & 0.000 & 0.000 & 0.000 & & - & - & - \\
\hline \multirow{2}{*}{ Responsiveness } & $\mathrm{r}$ & $0.477 * *$ & $0.470 * *$ & $0.520 * *$ & $0.583 * *$ & $0.628 * *$ & 1 & - & - \\
\hline & P-value & 0.000 & 0.000 & 0.000 & 0.000 & 0.000 & & - & - \\
\hline \multirow{2}{*}{ Flexibility } & $\mathrm{r}$ & $0.536^{* *}$ & $0.423 * *$ & $0.503 * *$ & $0.497 * *$ & $0.532 * *$ & $0.564 * *$ & 1 & - \\
\hline & P-value & 0.000 & 0.000 & 0.000 & 0.000 & 0.000 & 0.000 & & - \\
\hline \multirow{2}{*}{ Communication } & $\mathrm{r}$ & $0.509 * *$ & $0.557 * *$ & $0.578 * *$ & $0.611 * *$ & $0.563 * *$ & $0.498 * *$ & $0.558 * *$ & 1 \\
\hline & $\mathrm{P}$-value & 0.000 & 0.000 & 0.000 & 0.000 & 0.000 & 0.000 & 0.000 & \\
\hline
\end{tabular}

** Sig. $<0.5$

Finally, the study determines a positive and meaningful relationships between cognitive dimension and all seven components of workforce agility including intelligence $(\mathrm{r}=0.492, \mathrm{P}$-value $=0.000)$, maturity $(\mathrm{r}=0.546, \mathrm{P}$-value $=0.000)$, hard-working $(\mathrm{r}=0.491$, $\mathrm{P}$-value $=0.000)$, creativity $(\mathrm{r}=0.507, \mathrm{P}$ value $=0.000)$ and being responsiveness $(\mathrm{r}=0.477, \mathrm{P}$-value $=0.000)$, flexibility $(\mathrm{r}=0.536$, $\mathrm{P}$-value $=$ $0.000)$ and communication $(\mathrm{r}=0.509, \mathrm{P}$-value $=0.000)$.

\section{Conclusion}

In this paper, we have presented an empirical investigation to study the relationship between knowledge sharing and workforce agility. Using Pearson correlation ratio, the study has detected positive and meaningful relationships between various components of knowledge sharing, structural, relational and cognitive, and workforce agility $(\mathrm{r}=0.708, \mathrm{P}$-value $=0.001)$. The results of this study are consistent with the earlier results reported by Qin and Nembhard (2010), Breu et al. (2002).

\section{Acknowledgement}

The authors would like to thank the anonymous referees for constructive comments on earlier version of this paper. 


\section{References}

Breu, K., Hemingway, C. J., Strathern, M., \& Bridger, D. (2002). Workforce agility: the new employee strategy for the knowledge economy. Journal of Information Technology, 17(1), 21-31.

Gruber, T. R. (1995). Toward principles for the design of ontologies used for knowledge sharing?. International journal of human-computer studies, 43(5), 907-928.

Iravani, S. M., \& Krishnamurthy, V. (2007). Workforce agility in repair and maintenance environments. Manufacturing \& Service Operations Management,9(2), 168-184.

Li, Y. (2012, October). Workforce agility metric in EIS. In Information Management, Innovation Management and Industrial Engineering (ICIII), 2012 International Conference on (Vol. 2, pp. 422-425). IEEE.

Muduli, A. (2013). Workforce Agility: A Review of Literature. IUP Journal of Management Research, 12(3), 55-65.

Neches, R., Fikes, R. E., Finin, T., Gruber, T., Patil, R., Senator, T., \& Swartout, W. R. (1991). Enabling technology for knowledge sharing. AI magazine, 12(3), 36.

Qin, R., \& Nembhard, D. A. (2010). Workforce agility for stochastically diffused conditions-A real options perspective. International Journal of Production Economics, 125(2), 324-334.

Rodina, E., Zeimpekis, V., \& Fouskas, K. (2003, June). Remote workforce business processes integration through real-time mobile communications. In Proceedings of $2^{\text {nd }}$ International Conference on Mobile Businesses, Vienna. McGraw-Hill.

Sherehiy, B., Karwowski, W., \& Layer, J. K. (2007). A review of enterprise agility: concepts, frameworks, and attributes. International Journal of Industrial Ergonomics, 37(5), 445-460.

Tsai, W. (2002). Social structure of "coopetition" within a multiunit organization: Coordination, competition, and intraorganizational knowledge sharing. Organization Science, 13(2), 179-190. 